\title{
Notas sobre o conservadorismo político de Michael Oakeshott (1901-1990)
}

\author{
Notes on Michael Oakeshott's political conservatism
}

\section{Felipe Gava Cardoso}

Pesquisador CAPES pelo Programa de Doutorado em Ciência Política, Universidade Federal de São Carlos (UFSCar), São Carlos, SP, Brasil gavacardoso@yahoo.com.br
Resumo: O objetivo principal deste artigo é analisar a concepção política do britânico Michael Oakeshott(1901-1990), especialmente nos textos On being conservative, On human conduct $\mathrm{e}$ The politics of Faith. O fio condutor dessa exposição será sua relação com o pensamento conservador: aspectos de continuidade, renovação, especificidade e diálogos.Para tanto, será necessário nos munirmos de uma definição mais rigorosa do termo "conservadorismo" (segundo Kirk) e apreciarmos, ainda que brevemente, o contexto intelectual anglófono em inícios do século XX. Deste modo, será possível realizar, dentro dos limites deste trabalho, um balanço sobre o caráter do conservadorismo sob a lente de Oakeshott, assim como sua contribuição para a renovação e sofisticação do pensamento político no século XX.

Palavras-chave: Michael Oakeshott (1901-1990); Teoria política contemporânea; Pensamento conservador; Estado e sociedade civil.

\begin{abstract}
The main objective of this paper is to investigate the political conception of British thinker Michael Oakeshott (1901-1990) as presented in the texts On being conservative, On human conduct and The Politics of Faith. The focus of this exhibition will be his tense relationship with the basic assumptions of the conservative thought, with which he establishes a dense dialogue, full of continuities, renovations and detailing aspects. For that, it is necessary to elaborate a stricter definition of "conservatism" (according to Kirk) and appreciate, albeit briefly, the intellectual context in the English-speaking early twentieth century. Thus, it will be possible to perform an assessment of the character of conservatism under the lens of Oakeshott, as well as his contribution to the renewal and sophistication of political thought in the twentieth century.
\end{abstract}

Keywords: Michael Oakeshott (1901-1990); Contemporary political theory; Conservative thought; State and civil society. 


\section{Introdução}

Quando Anthony Giddens e a "Terceira Via" se tornaram mundialmente conhecidos pela contribuição com o governo trabalhista de Tony Blair, a Inglaterra já trazia um histórico de proximidade entre acadêmicos e políticos de carreira no século XX. Uma dessas convergências se deu na década de 1980, durante o governo de Margareth Thatcher. Buscando respaldo teórico para seu conservadorismo, visto como excessivamente pedestre por opositores e aliados, a "Dama de Ferro" propôs à Rainha Elizabeth II que homenageasse Michael Oakeshott (1901-1990), à época professor aposentado da London School of Economics (LSE), com a prestigiosa Ordem dos Companheiros de Honra, voltada para recompensar grandes conquistas nos campos das artes e das ciências humanas. O presente foi prontamente negado pelo scholar (KURIAN, 2011, p. 137).

Ambos os fatos - ser apreciado pela liderança mais conhecida do conservadorismo britânico no final do século XX e negar a ordem nobiliárquica - dizem muito sobre a postura política e teórica de Oakeshott. Sucessor do esquerdista Harold Laski na cátedra de Ciência Política da LSE, o autor prezava por manter o trabalho intelectual distante do imediatismo político, exceção feita durante a II Guerra Mundial, quando se alistou na resistência ao nazismo (FRANCO, 2004, p. 56). Além desses fatos, é raro encontrar nas biografias de Oakeshott menções mais extensas sobre sua relação com a política prática: sabemos que, na década de 1930, expressava descontentamento com o cenário político europeu, marcado pela escalada extremista de ideologias como o nacional-socialismo e o marxismo. E na década de 1960, mostrou antipatia com relação ao ativismo estudantil na LSE (FULLER, 2003). Fora isso, optou pelo trabalho intelectual.

Esse desinteresse pela política cotidiana, aliado ao hermetismo de alguns de seus textos, contribuiu para a confusão de definições sobre seu modo de pensamento. Em nossa pesquisa de doutorado, encontramos, até o momento, as seguintes definições: neohobbesiano (TREGENZA, 2001, p. 618; PAREKH, 1995, p. 184), aristocrata (MILLER, 2001, p. 823), liberal cético (RILEY, 1994, p. 746), conservador liberal (LAKOFF, 1998, p. 435), "conservador cético" (GRAY, 2013), "liberalismo hobbesiano" (DEVIGNE, 1994, p. 21), "conservador não convencional" (SPITZ, 1976, p. 335) e até mesmo "direita intransigente" (Perry Anderson apud GERENCSER, 1999, p. 846). Por outro lado, Gerencser reconhece em Oakeshott um "democrático radical" (GERENCSER, 1999:845), o que demonstra o caráter elusivo de seus argumentos. Independentemente da dificuldade de definição, o autor foi considerado por Timothy Fuller, especialista em sua obra, como “[...] um dos mais importantes pensadores conservadores do século XX [...]” (FULLER, 2003) e “[...] um dos maiores experts em teoria conservadora $[\ldots]$ " por Suvanto (1997, p. 138).

Mais do que falta de rigor, a diferença nas definições nos indica um autor ambivalente, que por vezes adere ao conservadorismo e por outras abre margem para uma maior liberdade comportamental. De fato, a rica produção teórica de Oakeshott, que abrange as décadas de 1930 a 1980, apresenta oscilações tanto em conteúdo quanto em consistência, transitando entre o campo liberal e conservador, por vezes de forma indistinta.

\section{Conservadorismo: em busca de uma definição}

Para compreender o pensamento de Oakeshott, é necessário, antes, embasarmo-nos em uma definição mais sólida do significado de conservadorismo. As lutas políticas do século XX e XXI estigmatizaram o termo de forma pejorativa e confusa, atribuindo-lhe características que não necessariamente compõem seu quadro de referências. Por mais contraditório que possa parecer, os argumentos associados a um viés conservador passaram por transformações profundas desde que Edmund Burke (1729-1797) deu forma a essa concepção política. Ganhou-se em matizes, peculiaridades, tendências, intensidades e prioridades.

Igualar conservadorismo à direita política mais confunde do que esclarece, por reunir inadvertidamente no mesmo grupo tradicionalistas medievais e ateus; pró-mercado e intervencionistas; fanáticos e moderados; moralistas e céticos; liberais e conservadores; democratas e autoritários. Muller demonstra que o conservadorismo toma as mais variadas formas no transcorrer do tempo e no choque entre as diferentes perspectivas:

[...] conservadores defenderam realezas, monarquias constitucionais, aristocracia, democracia representativa e ditadura presidencialista; altos impostos e livre comércio; nacionalismo e internacionalismo; centralização e federalismo; neoliberalismo e welfare state. Defenderam religiões e o laicismo. Existem, sem dúvida, conservadores hoje em dia que não imaginam que conservadores do passado poderiam defender instituições muito distintas das que eles admiram hoje. (MULLER, 1997, p. 3)

Nota-se, portanto, a miscelânea de posicionamentos, todos encampados sob um mesmo termo. É grande a possibilidade de combinações: há uma gama de possíveis respostas a diferentes cenários e contextos políticos. Nesse sentido, a definição do cientista político Samuel Huntington parece apropriada: mais do que uma teoria imanentemente ligada a certas instituições e 
programas, o conservadorismo é uma visão de mundo posicional, ou seja, um movimento político que só toma contornos mais nítidos de acordo com a realidade que se lhe apresenta, com o agravante da heterogeneidade de ideias (HUNTINGTON, 1957, p. 455). Roger Scruton parece seguir a mesma linha de raciocínio ao afirmar que "[...] a essência do conservadorismo é inarticulada, e sua expressão, quando aparente, é cética [...]" (SCRUTON, 2001, p. 1).

Mas não convém exagerar. Apesar da possibilidade múltipla de combinações, as tendências dominantes associadas ao conservadorismo possuem valores que aparecem com certa constância. Segundo Muller, organizador do precioso Conservatism: an anthology, o campo do conservadorismo moderno, excluindo-se formas radicais de reacionarismo político, apresenta ideias recorrentes, ainda que percorra um amplo leque de posições políticas e ambivalências. $\mathrm{O}$ autor enumera estas ideias recorrentes da seguinte maneira:

1. Ceticismo em relação à eficiência de constituições escritas em detrimento de costumes e hábitos; 2. Papel dominante das práticas culturais e morais como mecanismos de freio às paixões humanas; 3. Ceticismo em relação a projetos de liberação dos indivíduos das autoridades socioculturais; 4 . Ênfase na família como instituição de socialização [...]; 5. A legitimidade da desigualdade e da necessidade de elites culturais, políticas e econômicas; 6 . Proteção da propriedade privada como função principal da ordem política; 7. Importância do Estado como garantidor da propriedade e da imposição da lei, ou seja, a necessidade de manutenção da autoridade política. (MULLER, 1997, p. 18)

Russell Kirk, renomado historiador do conservadorismo e autor do conhecido The conservative mind, avança na apresentação desses princípios. O autor elaborou em 1993, para fins de divulgação, o artigo Ten conservative principles. Vejamo-nos mais detidamente cada um desses princípios:

1) "Ordem moral duradoura": Este primeiro argumento traz como pressuposto a noção de certa estabilidade da natureza humana, ou seja: a despeito das imensas alterações decorrentes de processos históricos, que marcam cada época com um conjunto de peculiaridades, permanece atuando, em níveis subjacentes, uma matriz ontológica relativamente estável. Ainda que ganhe contornos específicos, esta natureza humana parece resistente a mudanças profundas, encarnadas na modernidade em projetos de engenharia social (ou seja, quando grupos políticos assumem o controle do Estado e, de posse dessa ferramenta, inicia um processo de modelação radical de comportamentos). É perceptível o antagonismo entre esta concepção e a tabula rasa lockeana, ou ainda com a propensão para o bem de Rousseau. O conteúdo dessa natureza humana sofre delineações as mais diversas de acordo com o autor em questão, prevalecendo noções de imperfeição, agressividade, pulsões instintivas, egoísmo, temor e desejo de segurança e conforto.

2) "Adesão a costumes, convenção e continuidade": "Conservadores [...] preferem o mal que conhecem ao mal que desconhecem. Ordem, justiça e liberdade, segundo eles, são os produtos artificiais de uma longa experiência social, que resulta de séculos de julgamento, reflexão e sacrifício [...]" (KIRK, 2014, p. 2). Edmund Burke (1729-1797), em seu clássico Reflexões sobre a Revolução em França, defende que a existência duradoura de certas instituições é um indicativo, em maior ou menor grau, do sucesso destas em prover à humanidade certos bens, sejam simbólicos, responsáveis, por exemplo, pela dotação de sentido à existência, pela regulação do convívio social, ou seja, pela geração de condições favoráveis. Família, religiões e formas políticas, entre outras, fazem parte desse acervo histórico que acumula saberes incompreensíveis plenamente pelos indivíduos isolados: há alguma razão para que estas instituições tenham prevalecido historicamente. É o que Roger Scruton defende quando diz que "[...] conservadores defendem certas posições, não porque eles têm argumentos a seu favor, mas porque eles as conhecem, vivem com elas, e encontram sua identidade ameaçada pelas tentativas de interferência sobre estas posições [...]" (SCRUTON, 2001, p. 2). É importante frisar que estas instituições podem ser "artificiais", ou seja, construídas historicamente, e não eternas. Por isso a necessidade de uma cultura de preservação daquelas instituições que a História ajudou a decantar.

3) "Princípio da prescrição": "É perigoso pesar cada questão com base no juízo e na razão particulares. O indivíduo é tolo, a espécie é sábia, declarou Burke" (KIRK, 2014, p. 2). Conservadores tendem a desconfiar da habilidade individual em conseguir manejar saberes capazes de compreender o real e suas 
tendências de longo prazo. Aterrados sob uma imensidão de eventos e processos históricos, imersos numa experiência particular, inebriados por teorias que apresentam soluções radicais sem comprovação concreta, a razão individual tem a propensão de generalizar conclusões parciais, de acreditar em ideias aparentemente corretas mas não aplicáveis, enfim, o indivíduo tende ao erro e detém capacidade limitada de conhecimento. Convém, portanto, confiar no acúmulo histórico de saberes. As tradições, costumeiramente criticadas pelo pensamento social na modernidade, são reabilitadas aqui.

4) "Princípio da prudência": decorrência da precariedade humana em termos de conhecimento, a proposta conservadora é de apegar-se à realidade existente ao invés de aderir entusiasticamente a propostas de revolução social, cujos efeitos nos são desconhecidos. Boas intenções não são suficientes para se fazer política: o histórico de crimes políticos em nome de um bem maior é suficientemente grande para embasar este tipo de precaução. $\mathrm{O}$ fato de que algumas ideias e projetos políticos possam parecer racionalmente superiores não quer dizer que sejam factíveis quando aplicados na realidade. Oakeshott dedicará especial atenção a este princípio no artigo Rationalism in politics.

5) "Princípio da variedade": "Para a preservação de uma diversidade saudável em qualquer civilização, devem sobreviver ordens e classes, diferenças em condição material e muitas formas de desigualdade [...]" (KIRK, 2014, p. 4). Talvez um dos princípios mais polêmicos de Kirk, o princípio da variedade afirma que é inevitável que haja estratificação social, independentemente do modelo político em voga. Vale lembrar que estas diferenças são também econômicas: não é possível a superação das diferenças de posse, de status e de renda. Mas não são apenas econômicas: por haver uma diferença de talentos, esforços e circunstâncias entre os indivíduos, é natural que o resultado das ações sociais seja também desigual: sempre haverá indivíduos mais inteligentes, capazes de fazer uma leitura mais aguçada da realidade, e, assim, lograr melhores resultados econômicos, políticos, culturais etc. A diferença qualitativa de atributos os mais diversos (beleza, riqueza, inteligência, relações interpessoais, carisma, oratória, prestígio, liderança, criatividade, resiliência psicológica frente a situações traumáticas, ambição, diligência, planejamento, espírito empreendedor etc.) pode ser mais ou menos aguçada, mas se fará sempre presente. Desqualifica-se, novamente, as metas de longo prazo das utopias igualitaristas.

6) "Princípio da imperfeição": "Quando se busca por utopias, o fim é o desastre [...]" (KIRK, 2014, p. 5). Muito semelhante aos princípios 3 e 4, Kirk enfatiza as derivações políticas decorrentes do pressuposto da falibilidade humana. Se somos propensos ao erro de juízo, convém nos apegarmos às “" [...] salvaguardas institucionais e morais antigas [...]" (KIRK, 2014, p. 5). Convém lembrar que Kirk - assim como Oakeshott - está falando a partir da perspectiva anglo-saxã, cujos aparatos políticos foram historicamente capazes de prover certa estabilidade e garantir direitos civis para parcelas significativas da população, ainda que com distorções e exclusões significativas. Comparativamente a outras realidades políticas, EUA e Inglaterra foram eficazes em propiciar sistemas sociopolíticos dotados de mais liberdade de ação individual, em consolidar a aplicação da constituição via Estado de Direito e em fomentar a criação de economias pujantes. Portanto, por contraditório que possa parecer, há flexibilidade no âmbito do conservadorismo: Edmund Burke, protagonista na história do pensamento conservador e sempre tão enfático na crítica à Revolução Francesa, também defendeu a independência das colônias americanas, na contramão de muitos políticos tidos como mais progressistas naquele período. Oakeshott também revela em seus textos que é necessária precaução no uso desses valores preservacionistas a outros contextos políticos: o mundo é pródigo em exemplos de países autoritários e miseráveis que ganhariam mais com mudanças - prudentes, segundo os conservadores - do que com conservação.

7) "Ligação próxima entre liberdade e propriedade". Para compreendermos este tópico, compensa apresentarmos uma breve passagem de Kirk:

Separe a propriedade de sua posse privada e o Leviatã se torna o senhor de tudo. [...] Propriedade privada tem sido um instrumento poderoso para ensinar responsabilidade aos homens e mulheres, por oferecer motivos para a integridade, por apoiar a cultura em geral, por elevar a humanidade acima 
do nível da mera labuta, por prover tempo livre para pensar e liberdade de ação (KIRK, 2014, p. 5)

Percebe-se um conjunto de motivos para a defesa da propriedade privada. Em primeiro lugar, um argumento que aparece frequentemente em autores liberais: a propriedade privada é um dos instrumentos de peso e contrapeso ao poder estatal. A multiplicidade de proprietários, desde que convertidos em agentes econômicos, auxilia no controle do nível de atuação do Estado e atua como reserva de poder ao inibir a expansão da ação de grupos políticos para níveis sociais mais capilarizados (como comportamentos privados e preferências, por exemplo). Scruton adiciona o fato de que é através da propriedade privada que o ser humano trava relações de socialização com os objetos de acordo com seus desejos e planos (SCRUTON, 2001, p. 92). Não devemos nos esquecer que, ao lado dessa visão instrumental da propriedade privada baseada em sua utilidade, ela é também signo de mérito e de esforço pessoal.

8) “Preferência pela comunidade voluntária sobre o coletivismo involuntário": existem conservadores mais afeitos ao comunitarismo, ou seja, à existência de vínculos sociais mais rígidos, normatizadores da vida social. Para estes, mais tradicionalistas, a individualidade teria pouco a oferecer ao indivíduo, pois significaria, a um só tempo, liberdade e crise de referências. Sem capacidade de elaborar uma moral por si só, desenraizado de qualquer ligação com o passado, o indivíduo moderno tornar-se-ia anômico, desorientado, permanentemente em crise. Dentro desta corrente, há gradações, que vão de Scruton (um monarquista constitucional) a de Maistre (a favor de um Estado forte de viés cristão).

Outros, no entanto, preferem o caminho da individuação, pois esta alternativa tornaria voluntária a aproximação entre indivíduo e coletividade. Esse segundo grupo se aproxima da retórica liberal: mesmo que reconheçam os riscos deste processo decisório na construção de si, defendem que o indivíduo é a instância mínima do social e deve ser responsável por suas escolhas e preferências, sendo preferível uma associação espontânea com a comunidade em seu entorno a regimes políticos que fomentariam um coletivismo autoritário. Como tentaremos demonstrar mais adiante, Oakeshott está mais próximo dessa tendência.

9) "Necessidade de limites prudentes sobre o poder e sobre as paixões humanas": ao longo do século $\mathrm{XX}$, é visível o recuo e perda de influência do conservadorismo de perfil autoritário e radical. Há a tendência de acomodação às instituições republicanas e democráticas pelas linhas majoritárias do conservadorismo, aproximando-se, novamente, dos liberais. Segundo Kirk, "o conservador pretende limitar e equilibrar o poder político para evitar a anarquia e a tirania" (KIRK, 2014, p. 6). A estabilidade de instituições políticas, com um sistema jurídico institucional consolidado (Estado de Direito) e endossado por certo grau de consenso, tem como virtude a inibição de dois cenários negativos que, apesar de muito distintos, têm uma característica em comum: ambos desabilitam a autoridade estatal, fundamental para o exercício da letra da lei, seja pela permissividade imprevisível da anarquia, seja pelo autoritarismo discricionário de um Estado de exceção. Ambos, ao abandonarem o que Oakeshott chama de rule of law, fazem com que o Estado não consiga garantir o cumprimento isonômico das normas estabelecidas. Se não há instituições confiáveis e um aparato jurídico capaz de exercer o cumprimento da lei, há o risco de sérios danos políticos à sociedade: autoritarismo, censura, violência social e política, crise de produção, expansão dos privilégios, imprevisibilidade, dirigismo moral e político etc.

10) "Reconciliação entre permanência e mudança": valores como prudência e moderação se tornaram dominantes no conservadorismo do pós-II Guerra. Formas arcaicas ou extremas de conservadorismo, que defendem um retorno a um passado mítico, geralmente opondo-se aos efeitos da modernidade (industrialismo, urbanidade, consumismo e alienação, liberdade de costumes, democracia etc.) foram se tornando cada vez mais marginais no arco político - associadas, mais e mais, ao título de reacionarismo e aceitando modos agressivos de se fazer política. Assim, tornou-se mais aceitável entre conservadores reconhecer a possibilidade de alterações gradativas no plano político e social. "Em suma, o conservador defende o progresso equilibrado e moderado; ele se opõe ao culto ao Progresso, cujos seguidores acreditam que tudo que é novo é necessariamente superior a tudo que é velho [...]" (Kirk, 2014, p. 7).

Eis os princípios do conservadorismo a partir do século XX segundo Russell Kirk. Repito: trata-se mais de uma aproximação do que de uma definição 
rígida, posto que existem inúmeras modalidades e combinações de conservadorismo, rivalizando entre si no mercado de ideologias políticas.

\section{Conservadores de língua inglesa no início do Século XX}

Feita a definição de conservadorismo, buscaremos traçar um esboço da produção intelectual conservadora na primeira metade do século XX. Isso se justifica pelo contraste entre os pensadores dominantes na cena anglo-saxã, o "centro de gravidade" do pensamento conservador (SUVANTO, 1997, p. 116), e a originalidade e força teórica de Oakeshott ${ }^{1}$.

Até meados do século XIX, as diferenças entre pensamento liberal e conservador ainda eram significativas. Havia antagonismo aberto entre facções políticas e pensadores e não se imaginava que, num futuro breve, haveria confusão entre ambas as escolas. Vejamos a tabela de Girvin (1994, p. 50) (Tabela 1). Uma óbvia redução, a tabela tem sua utilidade ao ressaltar as clivagens entre liberalismo e conservadorismo que se arrastam até a entrada do século XX:

Percebam a diferença entre o conservadorismo desta fase e os dez princípios de Kirk. A defesa de formas autoritárias de governo, o vínculo entre Igreja e Estado (com uma religião oficial), a aceitação de corporações protegidas no plano econômico (garantidoras de privilégios de nascimento), a oposição contundente a mudanças sociais de toda ordem e a adesão a teorias racistas e imperialistas passarão a compor, progressivamente, o campo do reacionarismo político. O conservadorismo do século XX se tornou, cada vez mais, liberal, principalmente no pós-II Guerra Mundial. E essa é uma das contribuições de Oakeshott, como veremos adiante (KIRK, 1994, p. 299).

$\mathrm{O}$ aprofundamento da Revolução Industrial e sua avalanche de mudanças sociais, em especial a emergência de uma classe operária concentrada em bolsões populacionais, vivenciando cotidianamente a precariedade das relações trabalhistas e se organizando para o combate político e sindical, precipitou a queda de certas barreiras entre liberais e conservadores. O movimento operário é, entre todos, o vetor mais vigoroso na aproximação entre ambas as correntes (KIRK, 1994, p. 303).

\footnotetext{
${ }^{1}$ Convém destacar que optamos por nos manter nos marcos do conservadorismo teórico, deixando para outra oportunidade o cotejamento possível com autores liberais, como Isaiah Berlin, e com políticos conservadores, como Winston Churchill, ambos atuantes nesse mesmo período histórico. R. G. Collingwood (1889-1943), por vezes citado juntamente com Oakeshott, também não será abordado pelo fato de possuir pontos de contato marginais com Oakeshott, não diretamente relacionados ao tema em questão.
}

Parece-nos não ser equivocado dizer que o pensamento conservador se encontra, assim, vivenciando um impasse. A mudança radical do contexto europeu inviabiliza a aplicação ipsis literis das ideias conservadoras, obrigando os intelectuais a um processo de revisão e de adequação à nova realidade. Caracterizamos, portanto, a entrada do século XX como um momento de desorientação do pensamento conservador, que, quando tenta se "acomodar à modernidade" (GIRVIN, 1994, p. 197), vê suas fronteiras identitárias se desintegrarem em contato com o liberalismo; e que quando tenta se manter indiferente às mudanças, perde em densidade $\mathrm{e}$ retorna a questões pontuais de cunho filosófico. É esta última tendência que prevalecerá na Grã-Bretanha do jovem Oakeshott.

Russell Kirk também vê sinais de crise do pensamento conservador no início do século XX. Afirma que o conservadorismo está "à deriva" (KIRK, 1994, p. 375) e que é "difícil encontrar algo que valha a pena ler" no período do entreguerras (KIRK, 1994, p. 411). O cenário intelectual anglo-saxão enfrenta dificuldades de encontrar autores de maior quilate, capazes de atualizar o conservadorismo. Como exemplos desse período, Kirk seleciona seis autores de maior repercussão. São eles: Arthur Balfour (1848-1930), William Mallock (1849-1923), George Gissing (1857-1903), George Santayana (1863-1952), Paul Elmer More (1864-1937) e Irving Babbit (1865-1933).

Nossa intenção, aqui, é apresentar resumidamente o cenário formativo e as possibilidades de intertexto de Michael Oakeshott, para destacar o valor de sua composição teórica, ao apresentar conceitos mais precisos e ao conseguir expressar preocupações até então latentes em textos de outros autores. Sem pretensão de análise, o que seria inviável dados os objetivos do artigo, optamos por agrupar as preocupações desses autores conservadores de inícios do século XX em quatro eixos temáticos.

Tabela 1. Linhas de divisão entre direita e esquerda durante o século XIX.

Table 1. Lines of division between right and left during the nineteenth century.

\begin{tabular}{ccc}
\hline Tema & Liberais & Conservadores \\
\hline Política & Constitucional & Autoritário \\
Religião & Tolerância & Vínculo Igreja/Estado \\
Economia & Individualismo & Corporativismo \\
Ideologia & Racionalismo & Tradição \\
Mudança & Progressiva & Estabilidade \\
Identidade & Nacionalismo & Imperialismo/Raça \\
\hline
\end{tabular}

Fonte: Girvin (1994, p. 50). 
Dois desses eixos se dirigem a problemas de ordem moral e religiosa: primeiramente, há o diagnóstico de que há uma corrosão moral se alastrando pelo Ocidente, corroendo o tecido social e desarticulando antigos vínculos de solidariedade e de sentido (KIRK, 1994, p. 391, 392, 400-447); como decorrência, há a defesa do resgate do cristianismo como forma de comunicação com o transcendente e dotação de sentido à vida (a religião como caminho para a salvação, ou seja, a religião como um valor em si, como fé) e também como mecanismo de contenção de comportamentos amorais (ou seja, a religião a partir de sua utilidade como ferramenta de reforço da coesão social e repressão de atos antissociais) (KIRK, 1994, p. 431, 443).

Os outros dois eixos se voltam para questões de ordem política e econômica. Trata-se da noção de que existem diferenças naturais entre os homens, algo inevitável e também desejável (por razões de mérito, de liderança e de variedade de existências) (KIRK, 1994:406; 428) - argumento que se dirige contra o movimento operário e as "ideologias coletivistas" (KIRK, 1994, p. 447); e de um discurso anticientifico e antimoderno, cético quanto ao progresso técnico em vigor na Europa da Revolução Industrial, dado que as mudanças colocam em xeque formas tradicionais de existência (Kirk, 1994, p. 381, 391) e arrastam os seres humanos para um futuro imprevisível, distante das estruturas sociais conhecidas.

Mallock dá vazão a este temor conservador com relação ao abandono progressivo das religiões, geradoras do que ele chama de "doença do mundo moderno" (KIRK, 1994, p. 400), a saber, a corrosão dos valores morais tradicionais:

Quando o Homem perde de vista as finalidades morais, sua degradação começa. Surge a degeneração, sem a possibilidade de absolvição; e autoconsciência e indiferença. [...] Se forem bem-sucedidos em revolucionar as convicções morais e o caráter da maioria dos homens, veremos quão perto a besta adormece da pele da humanidade. Mesmo entre aqueles em que o desejo habitual de fazer o certo ainda opera são corrompidos pela indiferença moral que acompanha a irreligião. (KIRK, 1994, p. 400)

Desprovido dos freios que a religião oferece, o ser humano tende a recair no nível da barbárie, pois haveria o estilhaçamento das concepções morais e a disseminação de comportamentos erráticos. Repete-se, assim, uma assertiva do conservadorismo clássico.

É também de Mallock a passagem mais contundente na crítica às "doutrinas da igualdade", encampadas por parcelas significativas do movimento trabalhista nascente. A igualdade é criticada como uma ilusão, dado que as desigualdades são naturais e, mais do que isso, desejáveis, já que estimula os indivíduos ao esforço e à indústria, inibindo a inércia e a acomodação. Os homens desejam a distinção de status e se revoltam apenas quando se encontram em situação de inferioridade e tomam consciência dela. É possível inferir que os movimentos igualitaristas são vistos como modos organizados de expressão de ressentimento e vingança:

Através da História, progresso de todo tipo, econômico ou cultural, foi produzido pelo desejo do Homem de desigualdade. Sem a possibilidade de desigualdade, um povo continua no precário nível de subsistência, como camponeses irlandeses; garantida a desigualdade, a pequena minoria de homens habilidosos transforma barbárie em civilização. Igualdade não beneficia ninguém. Frustra o homem de talento e reduz o pobre a uma pobreza mais abjeta. [...] Pois a desigualdade produz a riqueza das comunidades civilizadas, oferece um motivo que induz o homem a buscar habilidades superiores. (KIRK, 1994, p. 403).

Já More oferece um trecho significativo sobre o impacto da racionalização técnica sobre as sociedades ocidentais e a crise anômica daí decorrente. O progresso tecnológico catalisa a crise dos modelos tradicionais de existência:

Assim que contemplamos o mundo convertido em uma grande máquina gerenciada por engenheiros, nós gradualmente tomamos consciência da falta de sentido, do vazio do valor humano; a alma é esvaziada nesta glorificação da eficiência mecânica. E então nós começamos a sentir a fragilidade de tal credo quando confrontado pelos problemas reais da vida; descobrimos sua inabilidade em impor qualquer constrangimento às paixões humanas, ou de oferecer qualquer governo que possa gerar lealdade de espírito. E vendo estas coisas nós entendemos o medo que corrói a vida social. (KIRK, 1994, p. 440)

Percebe-se a presença de vários itens elencados por Kirk como princípios conservadores. Contudo, a forma de expressão nos parece um tanto anacrônica, rústica, parcelada e arqueando para a extremidade do campo político de direita. Ainda há pouco ou quase nada da aproximação orgânica com o liberalismo que viria décadas adiante.

Eis as preocupações básicas que animavam os pensadores conservadores na virada do século XIX e XX. Com a pobreza teórica do período entreguerras, será apenas após a II Guerra Mundial (1939-1945) que amplos setores do pensamento conservador compreenderão que não há possibilidade de recuo a uma realidade pré-moderna e que será necessário a construção de um novo repertório de ideias para lidar com o novo cenário. A acomodação às regras democráticas é um passo importante nesse reconhecimento da mudança. 
É assim que Girvin (ainda que use o termo "direita") compreende este período histórico:

Num nível formal, a direita se transformou após 1945. Antes disso, era dividida entre conservadores democráticos e a direita autoritária, que buscava minar as instituições democráticas. A mudança passou pela aceitação, por parte da direita, dos limites e da disciplina das instituições democráticas liberais e da competição política. Assim, a direita no período do pós-Guerra aceitou a competição eleitoral e as regras do jogo político dentro de um sistema pluralístico. Isso não ocorreu repentinamente, nem com a mesma intensidade. (GIRVIN, 1994, p. 97)

As transformações em meados de século serviram para reforçar o protagonismo inglês entre os conservadores, já que em outros países europeus, como Alemanha e França, os movimentos fascistas serviram para desmoralizar o conjunto das concepções reacionárias (que gravitavam em torno do nazifascismo), impactando também, num primeiro momento, no conservadorismo moderado - mesmo que as potências ocidentais vencedoras (EUA e Grã-Bretanha) fossem países de ampla aceitação das ideias conservadoras. Suvanto percebe com clareza este fenômeno:

A II Guerra parecia significar a derrota ideológica do conservadorismo, ainda que a vitória dos Aliados fora conquistada parcialmente graças a líderes conservadores. Na Alemanha derrotada, a ideologia parecia completamente destruída. Na França, houve tentativas de igualar conservadorismo à filosofia do governo de Vichy. Foi na Grã Bretanha que a ideologia encontrou seu melhor campo, devido à liderança vitoriosa de Churchill, ainda que, mesmo lá, houve debates sobre a mudança do nome do partido. (SUVANTO, 1997, p. 116)

É sobre esse pano de fundo que florescerá o pensamento de Michael Oakeshott. Vejamos mais de perto, finalmente, os argumentos do pensador britânico.

\section{Sobre ser conservador segundo Oakeshott}

[...] não é de todo inconsistente ser conservador em relação ao Estado e radical em relação a quase todas as outras atividades. (OAKESHOTT, 1991, p. 196).

Se no plano geral Oakeshott é continuador dessa tradição política, em determinados aspectos ele é um inovador, no sentido de categorizar com mais eficiência e renovar algumas das preocupações conservadoras. Isto se faz presente no conjunto de sua obra, bastante heterogênea, diga-se de passagem, em termos de temáticas: o autor circula, na maior parte de sua produção, pelos campos da História, Filosofia e Política. Ao considerarmos o tema do presente artigo, o texto On being conservative é a porta de entrada ideal para iniciar o debate.

O ponto de partida de Oakeshott é a afirmação de que o conservadorismo não é uma "ideologia" no acervo de concepções de mundo, posto que não é propriamente criado racionalmente e sistematicamente. Trata-se de uma "disposição", uma "propensão" ou mesmo um sentimento de "familiaridade" a valores e instituições (OAKESHOTT, 1991, p. 168). Portanto, não é um construto racional baseado em valores teleológicos: não há um projeto acabado de sociedade que deveria ser aplicado sobre a realidade existente; ao contrário: parte-se dela e do acúmulo de instituições que ao longo da história demonstraram na prática trazer resultados, de alguma maneira, positivos. A propensão conservadora é devedora do "[...] sentimento de quem tem algo a perder, que se aprendeu a valorizar [...]" (OAKESHOTT, 2009, p. 1).

Isso não impede Oakeshott de reconhecer a necessidade de mudanças. Soaria reacionário se defendesse a conservação pela conservação, posto que há uma infinidade de realidades sociais e contextos diferentes. "Existem, é claro, numerosas relações humanas em que uma disposição para ser conservador [...] não é particularmente apropriado" (OAKESHOTT, 2009 , p. 4). Apenas a observação atenta das realidades específicas possibilita o entendimento da propensão à conservação. Não custa relembrar que Oakeshott fala a partir da Grã-Bretanha, país que parece ter mais a ganhar com o sentimento de conservação do que regiões subdesenvolvidas do mundo, que convivem com a opressão e a miséria.

O que o autor nega é o que chama de "amor pela mudança" (OAKESHOTT, 2009, p. 3). A aprovação indiscriminada de mudanças - fenômeno marcante no século XX - parece ser um empreendimento arriscado, já que "[...] inovações produzem perda certa e ganhos possíveis. Portanto, o ônus da prova recai nos inovadores" (OAKESHOTT, 2009, p. 2). Quanto mais radicais as mudanças, maior o risco, menor a previsibilidade.

De boas intenções, o inferno está cheio: propostas baseadas na expectativa de bons resultados não são suficientes. O comedimento político exige considerar que há a possibilidade de que uma medida, visando a um bem maior, resulte em seu contrário. A combinação complexa de causalidades costuma gerar efeitos inesperados - a intervenção política apenas exaspera esse processo. Voltamos a Kirk: a realidade parece absorver mal os projetos de gabinete que são otimistas quanto a mudanças profundas no ser humano. E quanto 
maior a confiança em qualidades humanas para a realização de projetos de mudança (como honestidade, generosidade, solidariedade, altruísmo, boa vontade ou ações desinteressadas), maior o ceticismo do conservador.

Novamente surge o argumento da familiaridade: "um bem conhecido não é facilmente trocado por algo melhor desconhecido" (OAKESHOTT, 2009, p. 3). Apegar-se ao vantajoso que está à mão (porque ele existe e é vivenciado como ganho, e não porque é necessariamente justificável via razão); mudar eventualmente, desde que com precaução e "[...] oferecer algo modestamente melhor do que o presente [...]" (OAKESHOTT, 2007, p. 30) parece ser a tônica do texto. Em síntese:

Sempre que a estabilidade é mais rentável do que a melhoria, sempre que a segurança é mais valiosa do que a especulação, sempre que a familiaridade é mais desejável do que a perfeição, sempre que o erro acordado é superior à verdade controversa, sempre que a doença é mais sofrível do que a cura, sempre que a satisfação das expectativas é mais importante do que a própria justiça das expectativas, sempre que uma regra de algum tipo é melhor do que o risco de não haver regra alguma, uma disposição para ser conservador é mais apropriada do que qualquer outra; e em qualquer leitura da conduta humana, estas abrangem uma gama não desprezível de circunstâncias. (OAKESHOTT, 2009, p. 5)

Conclui o próprio Oakeshott em uma passagem ilustrativa desse sentimento:

Ser conservador, portanto, é preferir o familiar ao desconhecido, preferir o experimentado ao não experimentado, o fato ao mistério, o real ao possível, o limitado ao ilimitado, o próximo ao distante, o suficiente ao demasiado abundante, o conveniente ao perfeito, um presente sorridente a uma felicidade utópica. (OAKESHOTT, 2009, p. 15)

Esse comedimento político deve ser considerado como uma bússola para a relação entre indivíduo e Estado. Uma das marcas do conservadorismo oakeshottiano é a atenção dedicada ao indivíduo, visto como unidade básica da vida social e um ente a ser preservado dos excessos despóticos do Estado. João Pereira Coutinho, conhecedor de Oakeshott, equaciona com peculiar sagacidade a equação indivíduo - Estado da perspectiva dessa corrente conservadora:

[...] um governo modesto e prudente começará por reconhecer [...] a multiplicidade de valores e objetivos de vida que os seres humanos perseguem por sua conta e risco no contexto de uma sociedade pluralista. Essa afirmação tem várias implicações -e várias aplicações. O reconhecimento de um universo de escolhas pluralistas significa que não cabe ao poder político decidir a hierarquia de valores sob a qual todos os indivíduos terão de viver as suas vidas. Porque são os indivíduos que vivem essas vidas: $\mathrm{e}$ são eles que, falhando ou acertando, devem perseguir os objetivos que entendem sem a mão paternalista do Estado. (Coutinho, 2014, p. 101)

Decorre daí uma concepção do Estado como instrumento na garantia do livre funcionamento da sociedade civil, dada a "[...] multiplicidade de atividades humanas e variedade de opiniões [...]". Torna-se claro a crítica à visão do Estado tutelar e a defesa consistente da liberdade individual (OAKESHOTT, 1991, p. 190). Foge completamente, portanto, das tendências normativas de alguns conservadores à moda do século XIX, mais dispostos a direcionar comportamentos privados. Não é da alçada do Estado moralizar a sociedade civil: cabe a ele a garantia da existência de um quadro institucional (rule of law) capaz de resistir aos projetos coletivistas e permitir a máxima extensão possível de comportamentos.

[...] o que torna inteligível a disposição conservadora em política não tem nada a ver com leis naturais ou ordem divina, nem com moral e religião; é a observação da maneira corrente de se viver combinada com a crença de que governar é uma atividade específica e limitada, a saber, a provisão e vigilância de regras gerais de conduta, que devem ser entendidas não como planos de imposição de atividades, mas como instrumentos que permitem os cidadãos buscarem as atividades de sua própria escolha [...] (OAKESHOTT, 1991, p. 191).

Estabelecer o limite das funções estatais é uma preocupação que perpassa toda a obra de Oakeshott. Não caberia ao Estado guiar valores e práticas ou interferir na vida privada dos cidadãos. Como não se pode confiar na boa vontade dos indivíduos, deve haver artifícios legais de controle da extensão do poder. O Estado, assim como a atividade política em geral, deve cumprir um papel restrito, que não prejudique o livre desenvolvimento de indivíduos e associações, estes sendo entendidos como fontes da verdadeira energia e dinâmica da vida social: “[...] a imagem do governante é do árbitro cuja atividade consiste em administrar as regras do jogo, ou do líder que governa o debate de acordo com regras conhecidas, mas não participa dele [...]" (OAKESHOTT, 1991, p. 193). Dito de outra forma:

[...] o papel do governo não é impor outras crenças e atividades sobre seus cidadãos, não é tutelar ou educa-los, não é faze-los melhores ou mais felizes de outra maneira, não é dirigi-los, não é orienta-los 
coletivamente nas ações, não é lidera-los ou coordenar suas atividades para que não haja ocasião de conflitos; o papel do governo é meramente governar. Esta é uma atividade específica e limitada, facilmente corrompida quando combinada com qualquer outra [...] O papel do Estado é manter seus cidadãos em paz uns com os outros nas atividades em que eles escolheram para buscar sua felicidade. (OAKESHOTT, 2009, p. 9-10)

É o indivíduo, responsável por si mesmo, que executa decisões éticas, culturais e comportamentais. A autonomia moral da vida civil deve ser respeitada e preservada por um aparato legal que impeça que projetos políticos totalitários absorvam a sociedade civil via Estado. Segundo Oakeshott, “[...] não é de todo inconsistente ser conservador em relação ao Estado e radical em relação a quase todas as outras atividades" (OAKESHOTT, 1991, p. 196). Desenha-se, portanto, um conservadorismo peculiar, de viés individualista, que acentua a liberalidade de costumes e é pouco afeito à intromissão pública nos comportamentos privados. A visão do Estado tutelar, zeloso pela vida de seus dependentes, é de todo incoerente com a perspectiva oakeshottiana: "[...] não somos crianças em statu pupillari, mas adultos que não se consideram sob nenhuma obrigação de justificar suas preferências ao tomar suas próprias decisões". (OAKESHOTT, 2009, p. 9).

\section{Oakeshott e a conduta humana}

Levando em consideração que Oakeshott parte da defesa irrevogável das liberdades individuais, seria útil entendermos o modo pelo qual o autor funda uma teoria sobre práticas sociais, sobre o indivíduo e sua relação com o entorno, em suma, sobre o agenciamento de influências sociais pelo prisma individual. Selecionamos dois tópicos presentes no livro On human conduct, que tem repercussão decisiva no conservadorismo original do autor: as raízes históricas da individualidade no Ocidente e a noção de consciência reflexiva.

\section{Ocidente e individualidade}

Segundo Oakeshott, uma série de processos históricos ocorridos a partir do século XVI na Europa Ocidental favoreceu a emergência histórica da individualidade, criando condições para o surgimento de modelos societais e políticos modernos, tais como a democracia e o debate acerca dos direitos civis. Da teia de eventos históricos, Oakeshott destaca a emergência do capitalismo e a proliferação de novas formas de pensamento através das fraturas da sociedade medieval (OAKESHOTT, 1991, p. 370; OAKESHOTT, 1993a, p. 8, 23). Nesse sentido, a noção moderna de política é entendida como uma "[...] invenção europeia dos últimos 300 anos" (OAKESHOTT, 2006, p. 38). João Carlos Espada resume a especificidade das conquistas ocidentais no plano da política e da liberdade individual:

A liberdade, para o conservador oakeshottiano, consiste nesta possibilidade de usufruir de modos de vida descentralizados. Não se trata de uma liberdade abstrata, mas de uma liberdade que emergiu no Ocidente ao longo dos séculos, através de múltiplos arranjos particulares: limitação do poder político, liberdade religiosa, propriedade privada, garantias legais do indivíduo, etc. (Espada, 2014)

Vale dizer que o Ocidente e a modernidade não são responsáveis pela criação da individualidade, mas sim de condições para sua emergência histórica. Ao analisar Hobbes, Oakeshott deixa evidências de que é possível considerar certos elementos perenes no indivíduo. A menção à natureza humana não é ocasional em um conservador: seguindo os passos de Hobbes, o autor destaca certos traços constantes da existência humana, tais como a hostilidade potencial entre seres humanos (OAKESHOTT, 1993a, p. 36-37), a colisão de interesses inerente à vida social (OAKESHOTT, 1993a, p. 50), a propensão à corrupção universal (OAKESHOTT, 1993a, p. 64), o "egoísmo essencial" (FRANCO, 2004, p. 65) e o "mútuo interesse instrumental" como constituinte da interação social (OAKESHOTT, 1993a, p. 65).

A natureza humana que estamos considerando é a estrutura interna do homem individual, mesmo se ele fosse o único exemplo de sua espécie: estamos considerando o caráter de um solitário. Ele vive no mundo de suas próprias sensações e imaginações, desejos e aversões, prudência, razão e religião. Para seus pensamentos e ações, ele é responsável perante ninguém, apenas a si mesmo. (OAKESHOTT, 2000, p. 34)

Com a formação do Ocidente moderno, este indivíduo é obrigado a enfrentar dilemas e a tomar decisões, pois se vê mais solitário que nunca. Segundo Oakeshott, prevalecem três tipos de resposta: a moralidade dos laços comunais, a moralidade da individualidade e o indivíduo manqué.

A "moralidade dos laços comunais" é devedora das formas tradicionais de organização social, onde o apego às tradições é determinante para a conformação do comportamento individual. Tratam-se de formas pré-modernas de organização social, progressivamente abandonadas na medida em que a modernidade e o Ocidente se consolidam. Há um sentimento forte de pertencimento a uma coletividade. 
Nessas circunstâncias, há pouco espaço para ideias de mudança moral ou progresso; de fato, uma disposição a favor de mudanças em qualquer sentido é notavelmente ausente. 'O bem'é reconhecido como o bem comum da sociedade. $\mathrm{O}$ autoconhecimento de cada membro é o conhecimento de si como um membro do todo [...]. Ele é uma pessoa que nunca desfrutou do prazer e da responsabilidade de juízos privados. (OAKESHOTT, 1993a, p. 19)

Já a "moralidade da individualidade" subverte a relação de forças entre indivíduo e sociedade: reforça-se o papel da autonomia moral do indivíduo e a crise das referências tradicionais de ordenação social (OAKESHOTT, 1993a, p. 20). Essa é a moralidade dominante no Ocidente e é vista por Oakeshott como uma espécie de privilégio, já que há a oportunidade histórica do indivíduo ser senhor de suas próprias decisões. Isso significa liberdade e, ao mesmo tempo, responsabilidade: não é mais possível se esconder desejos e instintos sob o escudo das tradições como justificativa de suas escolhas morais. Devemos lembrar que, como uma construção histórico-social, há sempre a possibilidade de retrocessos, ou seja: a moralidade da individualidade é uma conquista de um processo civilizacional, uma conquista sob constante ameaça de indivíduos e sociedades que se opõem ao curso histórico do Ocidente. Esse ganho de autonomia não é unanimemente celebrado por todos.

Surge a figura do indivíduo manqué, ou seja, aquele que não se adequa à modernidade e sente falta da solidez e da segurança das regras das sociedades tradicionais. Desorientado e inclinado à anomia, sofre constantemente com o dever de arcar com suas próprias decisões e não vê sentido ou motivação para viver. $\mathrm{O}$ vácuo referencial do indivíduo manqué serve de matéria prima para movimentos totalitários, pois estes oferecem sentido existencial e sentimento de grupo. Regimes políticos teleocráticos (da direita à esquerda, de reacionários a revolucionários) tendem a capitalizar sobre o senso de desamparo e angústia (OAKESHOTT, 2003, p. 205), tornando-se uma ameaça à consolidação de regimes democráticos calcados na autonomia da valoração moral. (OAKESHOTT, 1991, p. 371; OAKESHOTT, 1993a, p. 23).

Nossa hipótese é que a leitura de Oakeshott dos processos históricos e essa clivagem de tipos individuais serão fundamentais na conformação do Estado e dos aparatos institucionais propostos em seus textos mais propriamente políticos. Define-se, assim, um conservadorismo de perfil moderno, capaz de compreender e valorizar as conquistas da modernidade e do Ocidente, especialmente o ganho de responsabilidade individual em seus atos - argumento que aproxima Oakeshott da matriz liberal.

\section{Consciência reflexiva e autonomia moral}

Mais adiante em On Human Conduct, Oakeshott procura marcar posição contrária às tendências dominantes na Psicologia e na Sociologia. Ambas as disciplinas, segundo o autor, são habitualmente inclinadas a abordar o indivíduo como resultante de um cruzamento de influências, minimizando, assim, o papel soberano dos indivíduos nesse agenciamento. $\mathrm{O}$ vetor de influência parece se orientar do todo para as partes, enquanto que as respostas individuais a esses vetores é minimizada.

Sobre a Psicologia, Oakeshott demonstra incômodo a respeito da vitimização dos indivíduos, das tentativas de tirar a responsabilidade de seus atos seja por "necessidades psíquicas", pelo "inconsciente" ou quaisquer tipos de causalidade que pretensamente operariam à revelia do indivíduo (OAKESHOTT, 2003, p. 22). Oakeshott enfatiza, assim, a ideia de um agente inteligente, ativo, formador de sua própria conduta num cenário de escolhas. O prisma da consciência na interpretação do real ganha força. $\mathrm{O}$ autor vai além: defende que "[...] uma crença é o que ela significa para quem acredita [...]" (OAKESHOTT, 2003, p. 22), ou seja, mais do que uma realidade objetiva, há uma alta dosagem de interpretação pessoal sobre os fatos.

$\mathrm{O}$ teor das críticas à tradição sociológica não é diferente. $\mathrm{O}$ enfoque, nesse caso, se dá sobre as formulações excessivamente sistêmicas, estruturais, científicas, baseadas em supostas "leis", que minimizam o papel dos indivíduos no tratamento das circunstâncias dadas e que se aproximam, equivocadamente, da epistemologia das ciências naturais (OAKESHOTT, 2003 , p. 24). Essa pretensão de enquadrar a miríade de comportamentos humanos em um formato teórico “[...] está distante de qualquer coisa reconhecível como engajamento na teorização sobre conduta humana [...]" (OAKESHOTT, 2003, p. 25) e é definida como "engenharia social" e "aritmética do comportamento" (OAKESHOTT, 1996, p. 65; OAKESHOTT, 2003, p. 94). Podemos observar aqui a incidência de teses conservadoras como a opacidade das ações humanas, a difícil intelecção das causas e efeitos e a precariedade valorativa da mente humana em termos de objetividade e razão (OAKESHOTT, 1991, p. 37).

Feita a crítica ao objetivismo científico - na melhor das hipóteses, uma ilusão, na pior, uma forma de mistificação e poder -, Oakeshott passa à descrição da ação humana enfatizando a tese de que o indivíduo não deve ser entendido como um derivado de causalidades. $\mathrm{O}$ centro de gravidade de sua teoria converge para o polo da responsabilidade individual em detrimento das estruturas sociais ao descrever a prática social como "[...] um ser humano respondendo à sua situação contingente ao fazer ou expressar isso ao 
invés de aquilo em relação a resultados esperados ou desejados e em relação, também, ao entendimento das condições" (OAKESHOTT, 2003, p. 32). A consciência reflexiva consiste, portanto, em um agente livre dotado de autonomia e capacidade de autodeterminação (OAKESHOTT, 1993b, p. 92; OAKESHOTT, 2003, p. 32, 36-37).

Mas há certos reparos de Oakeshott quanto a essa liberdade e autonomia. O escritor britânico não parece confiar que o indivíduo, per se, consiga totalizar as tendências da realidade social: não há transparência na vida, a existência transcorre em certa névoa, resistente ao intelecto humano. Por isso, mesmo que seja responsável por si mesmo, o indivíduo deve entender que a valoração moral e política passa pelo reconhecimento das tradições. Ou seja, para evitar o vazio moral, os indivíduos devem recorrer ao acervo cultural legado pela história humana, à "herança social", ao "acúmulo de entendimentos humanos" - argumento caro a Edmund Burke já no século XVIII (BURKE, 1965, p. 58; MILLER, 2001, p. 812). A tradição é entendida como as "conquistas de inúmeros indivíduos expressas em termos de regras e condições que especificam uma multiplicidade de práticas particulares. São práticas coletadas, não coletivas" (OAKESHOTT, 2001, p. 177; OAKESHOTT, 2003, p. 86-87). Não se deve confundir esse uso consultivo das tradições com o engajamento do indivíduo manqué: este adere cegamente em busca da eliminação de dúvidas; aquele procura nas tradições uma referência, algo opcional, uma sugestão, um conselho que o acúmulo de experiências do passado lhe lega. Assim, temos um conservadorismo mais voltado para as estruturas políticas do que para comportamentos individuais.

Afinado a Kirk (KIRK, 1976, p. 13), Oakeshott reconhece a imensa variedade de comportamentos humanos, que oferece resistência a um conhecimento de tipo científico. Especialmente no Ocidente, essa variedade é geradora de dissensões e conflitos - o que é parte constituinte da modernidade e é a fonte da fertilidade da sociedade civil. O que distingue o Ocidente do restante do mundo é essa capacidade de encorajar modos não violentos de coexistência das diferenças - processo permanentemente inconcluso e sob ameaça. O saudosismo de um "princípio unificante" (FROWE, 2007, p. 274) é um desafio constante que se agrava com o esgarçamento do tecido social e a perda de vínculos entre indivíduos, fenômeno caro à modernidade. Cabe ao Estado fortalecer instituições políticas que fomentem a convivência, na sociedade civil, dos mais diferentes projetos privados (OAKESHOTT, 2003 , p. 366), preservando o campo no qual “[...] as alternativas de conduta são virtualmente ilimitadas" (OAKESHOTT, 1993b, p. 44). Ou, segundo Franco:
"Nas circunstâncias da modernidade e seu individualismo, seria difícil encontrar um propósito comum capaz de unir os membros do Estado. É isso que faz a associação civil particularmente apropriada em tais circunstâncias" (FRANCO, 2003, p. 502).

Spitz critica o que ele chama de monadismo, afirmando que Oakeshott "[...] não acredita que haja sociedade ou comunidade, mas apenas indivíduos [...]", frase atribuída, não por coincidência, a Margareth Thatcher (SPITZ, 1976, p. 344). Esta crítica é compartilhada por Frowe (FROWE, 2007, p. 274). No entanto, apesar do fato de Oakeshott ser reticente quanto a projetos coletivos, a mediação dos agentes pode romper com a aparente onipresença do egoísmo. Nas palavras do autor, "[...] o mito do agente necessariamente egocêntrico é uma negação do papel da agência [...]" (OAKESHOTT, 2000, p. 53).

Conclui-se que a análise da conduta humana segundo Oakeshott é estrutural em seu entendimento da esfera política. Ao criticar o indivíduo manqué, o autor se afasta do conservadorismo nostálgico de um passado mítico, que busca recuperar formas de interação social progressivamente abandonadas. Ao mesmo tempo, a defesa da autonomia do indivíduo como sujeito de si o aproxima de uma perspectiva liberal; contudo, o ceticismo quanto ao potencial do indivíduo desenraizado, sem vínculos com o passado e a defesa do uso seletivo de referências e tradições demarca uma linha divisória com relação ao liberalismo mais ortodoxo. Eis a especificidade do conservadorismo de Oakeshott.

\section{Estado e sociedade civil em Oakeshott Fé e ceticismo}

Oakeshott vai além na análise da política moderna. Considerando as potencialidades e usos do Estado, tanto em sua estrutura quanto em sua função, o filósofo britânico nota uma profunda clivagem entre duas posturas, denominadas pelo autor como a "política da fé" e a "política do ceticismo".

Esses termos aparecem como complementares à dicotomia esquerda-direita, insuficientes e imprecisos - segundo o autor - para registrar as alternativas políticas modernas (OAKESHOTT, 1996, p. 21). A política da fé representa o conjunto de propostas políticas cujo núcleo está no otimismo quanto à busca da perfeição humana (OAKESHOTT, 1996, p. 23), ou seja, na visão de que o Estado seria o instrumento por excelência do aprimoramento humano. Essas ideologias tendem a crer que o homem é derivado basicamente de circunstâncias sociais - e como tal, a alteração dessas circunstâncias em nome da perfeição seria o método principal de se fazer política (OAKESHOTT, 1996, 
p. 24). Entre os riscos inerentes a essa visão estariam, segundo Oakeshott, a leitura das disputas políticas como um jogo de oposição entre verdade e erro, a política como atividade sem marcos institucionais limitadores (OAKESHOTT, 1996, p. 27), a educação como dispositivo para fortalecimento do poder (OAKESHOTT, 1991, p. 38; OAKESHOTT, 1996, p. 29) e, em seu extremo, a visão de que a legalidade seria um obstáculo ao progresso. Nessa perspectiva, o "poder nunca será excessivo" (OAKESHOTT, 1996, p. 28) e há forte tendência de se direcionar o comportamento coletivo de acordo com os interesses políticos (OAKESHOTT, 1991, p. 8-10), já que o governo assume o papel de "arquiteto paternalista" e "líder moral" (OAKESHOTT, 1991, p. 377).

A política da fé suporta posições que circulam por todo o espectro político. Oakeshott destaca três modelos principais de busca da perfeição social: religioso (como nas experiências de Lutero e Calvino), produtivista (na filosofia de Francis Bacon) e distribucionista (no pensamento marxista) (OAKESHOTT, 1993a, p. 92). O elo entre esses modelos seria a convicção de que suas propostas representam a única perspectiva correta em política. Todas as visões de mundo antagônicas se enquadrariam como inimigas ou como modalidades de ignorância. A passagem a seguir resume as preocupações de Oakeshott:

Buscadores da verdade na política são potenciais inimigos da liberdade de expressão, porque eles estão desprotegidos contra a crença de que eles atingiram seu objetivo. E o que faz a opinião popular uma influência corruptora sobre a conduta do governo é justamente a sua disponibilidade em acreditar que as fórmulas atuais representam 'a verdade'. (OAKESHOTT, 1993b, p. 116)

Já a política do ceticismo vê como utópicas e perigosas as tentativas de aperfeiçoamento ilimitado do humano (representados na imagem da torre de Babel, em History and Other Essays), pois parte do princípio de que, em sua maioria, os homens são propensos a atender aos seus próprios interesses e a se utilizar do poder e das relações sociais como instrumentos para angariar vantagens. Como derivados desses pressupostos aparecem a negação de um "caminho único" para o todo social (OAKESHOTT, 1996, p. 31); “[...] a ordem como uma conquista árdua, nunca fora do alcance da decadência e dissolução" (OAKESHOTT, 1996, p. 32); a necessidade de conter tendências de ruptura com a legalidade, protetora das liberdades; a importância de um alto grau de formalização institucional e de transparência (OAKESHOTT, 1996, p. 34); e a construção de regras de controle do exercício do poder, num jogo de pesos e contrapesos (OAKESHOTT,
1996, p. 42) para se evitar extremismos políticos de todo tipo (OAKESHOTT, 1996, p. 121). Percebe-se a preocupação de análise não apenas das metas e objetivos políticos de longo prazo, mas também dos procedimentos e ferramentais para atingi-los e os riscos implícitos dessas empreitadas (KALINER, 2004, 50).

Apesar da clara simpatia pela proposta cética, Oakeshott identifica fragilidades em ambas: "Considerando que a fé sofre o perigo do excesso, o ceticismo sofre o perigo de moderação [...]" (FROWE, 2007, p. 271), ou seja: se na política da fé não há limites para a expansão do exercício do poder, no ceticismo há o risco de desagregação e apatia quanto ao destino político, antessala para movimentos radicalizados. No limite, portanto, a política do ceticismo peca em oferecer motivações para a participação política e a preservação de conquistas, abrindo caminho para os defensores da política da fé.

No Brasil, de modo pioneiro, Daniel Marchiori apresenta uma produção bastante madura a respeito de Oakeshott. Na passagem a seguir, ele define de maneira precisa as diferenças na intervenção estatal em termos de políticas de fé e de ceticismo e o modus operandi de um estadista cético:

[...] para o cético, a intervenção estatal é exigida para aprimorar os arranjos e práticas institucionais vigentes, corrigindo defeitos visíveis e específicos; para a fé, a intervenção serve para colocar em prática estruturas e modelos idealizados. Conseqüentemente, a maneira como o estadista cético arbitra suas escolhas é diferente. Primeiro, ele não possui explicitamente uma preferência sobre algum modelo padronizado de transformação social; segundo, tende a preferir modelos mistos e flexíveis a modelos totalizantes; terceiro, sua escolha é colocada em prática não com a finalidade de impor cegamente a proposta, mas está sempre atento caso haja necessidade de tomar desvios; quarto, ele somente escolhe aquilo que os meios the permitem, atrelado à lógica do economicamente possível; quinto, procura solucionar as necessidades históricas do momento vivido, dos problemas atuais, sem apegar-se demasiadamente ao futuro. Portanto, o cenário do cético é o da incerteza e da imprevisão. Como não sabe dos resultados vindouros, bem como se questiona continuamente a necessidade de suas ações, procura utilizar sempre a menor quantidade possível de poder. (MARCHIORI NETO, 2009, p. 22)

A dicotomia sugerida por Oakeshott cumpre múltiplas funções: renova o repertório analítico em política; contribui para uma separação inovadora de projetos políticos; indica modos de atuação política mais adequados para a preservação de conquistas sociais; reforça a importância do aparato institucional como inibidor de excessos de poder; favorece a autonomia 
de múltiplas instituições da sociedade civil: escola, imprensa, partidos políticos, Estado etc. Além disso, não elimina a possibilidade de intervenção do Estado: apenas orienta essas intervenções para que sejam mais modestas e que considerem a possibilidade de um "paradoxo das consequências".

\section{Tipos de associação}

Paralelamente a essa dicotomia, Oakeshott apresenta um outro par conceitual de grande valor para a avaliação de modelos de organização. O par é formado pelo que o autor denomina de enterprise association (algo como associação de empreendimento ou de iniciativa) e de civil association (associação civil). O propósito principal parece ser a demarcação do grau de intervenção legítima das instituições sobre os indivíduos, preocupação cara às tendências liberais.

A enterprise association é caracterizada pela ação conjunta voluntária, suscetível a abandono durante o processo e a regras estritas definidas pelo grupo em questão. Repito: trata-se de uma associação voluntária. Quem participa opta por isso e pode deixar a instituição assim que desejar. Há o engajamento em comum a causas e objetivos estabelecidos pelo grupo, com a livre aceitação de regras e comandos especificados por códigos internos ao grupo (OAKESHOTT, 2003, p. 315). O grau de dedicação é definido pelo livre acordo entre indivíduo e organização. Para Oakeshott, esse é um modelo organizativo mais adequado a empresas, partidos, ONG's, associações comunitárias, artísticas, intelectuais etc, ou seja, quaisquer organizações possíveis na sociedade civil (OAKESHOTT, 2003, p. 182), mas inapropriado para o Estado (FROWE, 2007, p. 273). É um mecanismo adequado à efervescência da vida civil, mas não deve ser transposto para o conjunto da sociedade, já que não haveria, nesse caso, chance de não-adesão. Sendo a subordinação ao Estado um ato compulsório, a imposição de regras deve se restringir ao mínimo possível.

Quando grupos políticos rompem o limite de atuação da sociedade civil e estendem sua lógica ao Estado, há o risco de autoritarismo. Devigne equaciona com precisão a postura oakeshottiana frente a essas concepções do fazer político:

Problemas políticos surgirão assim que o Estado adote um modelo de associação de empreendimento: o Estado se torna uma instituição propositiva; leis se tornam instrumentos para buscar metas substantivas; o Estado compele a sociedade a se reorganizar de acordo com as demandas do grupo político mais poderoso. (DEVIGNE, 1994, p. 156)

Já a civil association (associação civil) é uma comunidade involuntária de pessoas baseada em necessidades de socialização e convívio, demarcada pelos limites do próprio Estado que não segue regras de afinidade por objetivos, posto que seus membros não perseguem metas em comum (OAKESHOTT, 2003, p. 182), mas coexistem no mesmo espaço e precisam de um mínimo de regras de convivência. É uma “[...] relação formal em termos de regras, não uma relação substantiva em termos de ação comum”. Caberia à multiplicidade de interesses presentes na sociedade civil criar suas organizações de interesse; ao Estado, cabe o papel regulatório dos limites de ação, ancorado em "legalidade"; "formalização" e "institucionalidade" (OAKESHOTT, 2003, p. 201), apto a exercer "coerção" com autoridade e soberania (OAKESHOTT, 1993a, p. 41,44) no momento em que projetos políticos particulares ultrapassem seus limites, colocando em risco a autonomia individual e as liberdades civis. Dito de outro modo:

Governar é uma atividade específica e limitada: a de um árbitro em vez de um líder ou gestor; as energias de uma comunidade não devem ser subservientes a um objetivo central, um 'sonho privado' transformado em um ídolo coletivo pela força e persuasão: em vez disso, eles devem ser autorizados a estimular os canais de atividades variadas, cada um com sua teleologia própria genuína e espontânea; a tarefa do governo consiste em moderar a dissonância inevitável entre os esforços dos 'homens apaixonados' e prevenir rupturas. A inovação não pode ser dispensada: deve responder - orientar, corrigir e canalizar - as correntes de mudança social, em vez de ser perseguida como um plano primário e abrangente. (KOLNAI, 1965, p. 70)

Assim, o objetivo da ação estatal não seria definir modos de vida, mas garantir uma espécie de pacto social que permite a existência livre de empreendimentos. A ordenação política é vista como um quadro de direitos, deveres e meios de fiscalização, constituindo o que Oakeshott chama de "ordem superficial” (OAKESHOTT, 1996, p. XIX). O papel do Estado é reduzir a possibilidade e a gravidade de conflitos (FROWE, 2007, p. 268), sem afetar o livre funcionamento da sociedade civil.

Para este conservador, o primeiro requisito de um regime político será a proteção da sua casa, isto é do seu modo de vida. Ele não pede ao regime político que lhe diga como deve ser a sua casa, apenas que a proteja. Em contrapartida, também não quer dizer ao vizinho como deve ser a casa dele. Não espera, portanto, que o regime político o faça. Por outras palavras, o conservador oakeshottiano nunca verá a ação política como sede de uma atividade cujo propósito pudesse ser desenhar os modos de vida das pessoas. (ESPADA, 2014) 
Defendemos que o argumento de Oakeshott transita entre a apreciação da natureza da sociedade civil e o papel regulador do Estado. Se ele se volta constantemente para a questão da estrutura e função do Estado é porque está preocupado com a fragilidade que ronda a existência espontânea de forças sociais criativas na sociedade civil, onde ocorre uma "espécie de diálogo entre uma variedade de atividades humanas" (DEVIGNE, 1999, p. 135-136). Este é o ineditismo da invenção europeia de 300 anos: não há paralelo histórico em outras sociedades de um espaço de liberdade para os indivíduos buscarem sua felicidade no exercício da liberdade.

O espírito de Respublica (OAKESHOTT, 2003, p. 182) é fundamental para a prática da civilidade sem especificação de performances por parte do Estado. Este deve oferecer condições (através de um aparato legal mínimo e pouco invasivo de defesa dos direitos dos cidadãos) para que cada um persiga seus próprios objetivos com o mínimo de aliciamento externo. Afinal, para Oakeshott, a política moderna conquistada pelo Ocidente é a "atividade na qual uma sociedade lida com a diversidade" (OAKESHOTT, 2006, p. 35). Esse é o bem maior a ser preservado. Ou, segundo Devigne:

[...] um Estado não existe para servir a interesses e propósitos comuns, mas para sustentar uma estrutura de regras e convenções dentro da qual condutas télicas e interpessoais possam ser mantidas (DEVIGNE, 1994, p. 18)

\section{Conclusão}

Esperamos, à essa altura do artigo, ter elencado o essencial de nosso propósito. Finalizaremos com a recapitulação e desenvolvimento de algumas conclusões. Vejamos:

1) Se a definição de Russell Kirk não esgota o problema da definição do que é "conservadorismo", ela ao menos norteia as possibilidades de um melhor entendimento. Mais do que isso: explicita o fato de haver conservadorismos, no plural. São inúmeras as possibilidades de combinação dos "dez princípios" conservadores: diferenças de relevância, de radicalidade ou moderação, de contextualização sócio-histórica e mesmo de conflito entre eles. Há uma gama extensa de conservadorismos possíveis.

Oakeshott se aproxima de todos os itens de Kirk, ressalva feita aos itens 1

(“ordem moral duradoura") e 3 ("princípio da prescrição"). O autor não parece tão convicto da estabilidade da natureza humana, ou pelo menos não se arrisca a adjetiva-la extensivamente. Quanto à racionalidade, Oakeshott é mais inclinado a crer na responsabilização dos indivíduos sobre seus atos ("consciência reflexiva"), mesmo que o uso consultivo das tradições lhe pareça importante.

2) Ao observarmos a descrição de Kirk sobre o contexto intelectual conservador de língua inglesa em inícios do século XX, nos deparamos com um cenário de desorientação e de crise. Os autores considerados relevantes no campo conservador naquele momento (Balfour, Mallock, Gissing, Santayana, More e Babbit) teriam uma repercussão declinante ao longo do século (exceção feita, talvez, a Santayana). Além disso, apesar das peculiaridades de cada um, parecem afeitos a um conservadorismo de difícil operacionalização e fadado ao anacronismo histórico, preocupado em fazer uma crítica à corrosão moral, às ideologias coletivistas e aos riscos da ciência e da tecnologia. Respondem a este cenário defendendo o reforço do cristianismo, a defesa da aristocracia e a exaltação do passado.

Parece haver pouca possibilidade de interlocução entre os conservadores supracitados e Oakeshott, o que nos dá sinal de como o autor revigora o conservadorismo ao aproximá-lo de certas propostas liberais, tornando-o mais inteligível à cena intelectual do século XX e XXI.

3) O conservadorismo de Oakeshott é visto como uma propensão, que toma formas específicas de acordo com o que o contexto sócio-histórico em questão oferece. O corpo de sua argumentação consiste na defesa de uma "formulação minimalista" do Estado (COUTINHO, 2012, p. 38), no sentido de inviabilizar a imposição de projetos ambiciosos de engenharia social. A história de formação do Ocidente deixou como legado o surgimento de um novo perfil de individualidade, dotado de "consciência reflexiva" e autonomia moral para estabelecer seus próprios interesses e modos de vida, dispensando a tutela do Estado ou de quaisquer ideologias. É possível reconhecer certa aproximação com o liberalismo na defesa irrevogável da individualidade e na necessidade de limitação do poder Estatal.

4) Parte da contribuição de Oakeshott está em "acertar os ponteiros" (COUTINHO, 2012, p. 28), ao discernir dois blocos de projetos 
políticos ("política da fé" e "política do ceticismo") e dois modelos de associação ("enterprise association" "e "civil association"). Ambas ajudam a entender os perigos de uma política transgressora do espaço individual, que busque redesenhar as relações sociais com base exclusivamente na razão, destacando-se do acúmulo de lições históricas e da prudência. No espaço da sociedade civil, os indivíduos podem travar as relações que acharem desejáveis, posto que se trata de relações voluntárias; como não é possível submeter-se ao Estado voluntariamente, deve haver um maior cuidado nos seus modos de atuação e restringir-se a um mínimo institucional (segurança e ordem). Daí a peculiaridade de Oakeshott: é prudente e conservador com relação a mudanças institucionais e a intervenção excessiva do Estado, mas aceita - e estimula - a liberdade comportamental na sociedade civil. No limite, não seria incoerente, portanto, pensar que alguém inspirado no pensamento de Oakeshott aderisse a causas geralmente vistas como progressistas (ou "liberais" no sentido americano do termo), como, por exemplo, o combate a todas as formas de preconceito (de gênero, de raça, de classe, de sexualidade etc) e mesmo a adesão a políticas distributivas.

5) Sob pena de simplificação, podemos dizer que são contribuições de Oakeshott ao pensamento conservador: renovação do repertório analítico no campo da Filosofia Política; discernimento de diferentes estratégias políticas e investigação de seus riscos e méritos; reforço da importância de um aparato institucional universalmente aceito e funcional, que propicie a livre fruição da individualidade aos seus cidadãos; defesa incondicional da autonomia da sociedade civil como fonte criadora da dinâmica social (a ser defendida do poder estatal); uso consultivo e seletivo das tradições, com base em seus resultados práticos; aproximação do conservadorismo às problemáticas liberais, sem perda identitária; e afastamento do viés moralizante e retrógrado do conservadorismo inglês da virada do século XIX para o XX.

A passagem abaixo parece sintetizar o conservadorismo de nova roupagem elaborado por Oakeshott:

[...] o que faz uma disposição conservadora inteligível em política não tem nada a ver com a lei natural ou uma ordem providencial, nada a ver com a moral ou religião; é a observação do nosso modo de vida atual combinado com a crença (que, do nosso ponto de vista tem de ser considerada nada mais do que uma hipótese) de que governar é uma atividade específica e limitada, ou seja, a disposição e custódia de regras gerais de conduta, que são entendidas, não como os planos para a imposição de atividades substantivas, mas como instrumentos que permitam as pessoas a exercer a atividade de sua escolha com o mínimo de frustração e, portanto, algo sobre o que convém ser conservador. (OAKESHOTT, 2009, p. 8)

\section{Referências}

BURKE. E. Reflections on revolution in France. New York: Merrill, 1965.

COUTINHO, J. P. As ideias conservadoras. São Paulo: Três Estrelas, 2012.

COUTINHO, J. P.; PONDÉ, L. F.; ROSENFIELD, D. Por que virei à direita. São Paulo: Três Estrelas, 2012.

DEVIGNE, R. Recasting conservatism: Oakeshott, Strauss and the response to Postmodernism. Chelsea: Yale University Press, 1994.

DEVIGNE, R. The Legacy of Michael Oakeshott. Political Theory, Sage Publications, v. 27, n. 1, p. 131-139, 1999. http://dx.doi.org/10.1177/00905917 99027001008.

ESPADA. J. C. Michael Oakeshott e a disposição conservadora. 2014. Disponível em: <http://www. midiasemmascara.org/artigos/conservadorismo/12756michael-oakeshott-e-a-disposicao-conservadora.html>. Acesso em: 17 jun. 2014.

FRANCO, P. Oakeshott, Berlin and Liberalism. Political Theory, Sage Publications, v. 31, n. 4, p. 484-507, 2003. http://dx.doi.org/10.1177/0090591703254385.

FRANCO, P. Michael Oakeshott: an Introduction. London: Yale University Press, 2004.

FROWE, I. 'The politics of faith and the politics of scepticism': Michael Oakeshott, education and extremism. British Journal of Educational Studies, Cambridge, v. 55, n. 3, p. 264-285, 2007. http://dx.doi. org/10.1111/j.1467-8527.2007.00379.x.

FULLER, T. The Work of Michael Oakeshott. Political Theory, v. 19, n. 3., p. 326-333. 2003.

GERENCSER, S. A democratic Oakeshott? Political Research Quarterly, Sage Publications, v. 52, n. 4, p. 845-865, 1999.

GIRVIN, B. The right in the twentieth century. London: Pinter Publishers, 1994.

GRAY, J. Margareth Thatcher unintended legacies. Washington: New Republic, 2013. Disponível em: $<$ http://www.newrepublic.com/article/114223/margaretthatcher-reviewed-john-gray>. Acesso em: 19 jul. 2014.

HUNTINGTON, S. P.. Conservatism as an ideology. The American Political Science Review, v. 51, n. 2, p. 454-473, 1957. http://dx.doi.org/10.2307/1952202. 
KALINER, M.; TELES, S. The public policy of skepticism. Perspectives on Politics, v. 2, n. 1, p. 39-53, 2004. http://dx.doi.org/10.1017/S1537592704000611

KIRK, R.. Rationalism in politics and other essays by Michael Oakeshott. The Annals of the American Academy of Political and Social Science, v. 347, p. 181, 1976.

KIRK, R. The conservative mind: from Burke to Eliot. Washington, DC: Regnery, 1994.

KIRK, R. Ten conservative principles. Mecosta: The Russell Kirk Center, 2014. Disponível em: <http:// www.kirkcenter.org/index.php/detail/ten-conservativeprinciples>. Acesso em: 20 may. 2014.

KOLNAI, A. Rationalism in politics and other essays by Michael Oakeshott. Philosophy, v. 40, n. 151, p. 68-71, 1965. http://dx.doi.org/10.1017/S0031819100052463.

KURIAN, G. (Org.). The encyclopedia of political science. Washington: Sage Publications, 2011.

LAKOFF, S. Tocqueville, Burke, and the origins of liberal conservatism. The Review of Politics, v. 60, n. 3, p. 435-464, 1998. http://dx.doi.org/10.1017/ S003467050002742X.

MARCHIORINETO, D. L. Política de ceticismo e intervenção estatal: uma crítica liberal ao conservadorismo liberal de Michael Oakeshott. In: WORLD CONGRESS OF POLITICAL SCIENCE, 21., 2009, Santiago. Anais... Santiago: IPSA, 2009.

MILLER, T. H. Oakeshott's hobbes and the fear of political rationalism. Political Theory. Sage Publications, v. 29, n. 6, p. 806-832, 2001. http://dx.doi.org/10.1177 /0090591701029006005.

MULLER, J. (Org.). Conservatism: an anthology of social and political thought. New Jersey: Princeton University Press, 1997.

OAKESHOTT, M. Rationalism in politics and other essays. Indianapolis: Liberty Fund, 1991.

OAKESHOTT, M. Morality and politics in modern Europe. London: Yale Press, 1993a.

OAKESHOTT, M. Religion, politics and moral life. London: Yale Press, 1993b.
OAKESHOTT, M. The politics of faith \& The politics of scepticism. London: Yale Press, 1996.

OAKESHOTT, M. Hobbes on civil association. Indianapolis: Liberty Fund, 2000.

OAKESHOTT, M. The voice of liberal learning. Indianapolis: Liberty Fund, 2001.

OAKESHOTT, M. On human conduct. New York: Oxford University Press, 2003.

OAKESHOTT, M. Lectures in the history of political thought. Charlottesville: Imprint Academic, 2006.

OAKESHOTT, M. The concept of philosophical jurisprudence: essays and reviews. Charlottesville: Imprint Academic, 2007.

OAKESHOTT, M. On being conservative. Riverside Community College District, 2009. Disponível em: $<$ http://faculty.rcc.edu/sellick/On\%20Being\%20 Conservative.pdf $>$. Acesso em: 03 mar. 2014.

PAREKH, B. Oakeshott's theory of civil association. Ethics, University of Chicago Press, v. 106, n. 1, p. 158-186, 1995.

RILEY, P. Morality and politics in modern Europe: the Harvard lectures. by Michael Oakeshott. The American Political Science Review, v. 88, n. 3, p. 746-748, 1994. http://dx.doi.org/10.2307/2944821.

SCRUTON, R. The meaning of conservatism. London: Palgrave, 2001.

SPITZ, D. A rationalist malgré lui: the perplexities of being Michael Oakeshott. Political Theory, Sage Publications, v. 4, n. 3, p. 335-352, 1976.

SUVANTO, P. Conservatism from the French Revolution to the 1990's. New York: St. Martins Press, 1997.

TREGENZA, I. Skepticism and democracy in Michael Oakeshott's political theory. The Review of Politics, v. 63 , n. 3 , p. $617-620,2001$

Recebido: 05 fev., 2015 Aceito: 21 abr., 2015 